\title{
Effect of storage on the fatty acids of dried ryegrass
}

\author{
BY J. W. CZERKAWSKI \\ Hannah Dairy Research Institute, Ayr \\ (Received 7 November 1966-Accepted I4 March ${ }_{9} 967$ )
}

\begin{abstract}
I. The compositions of the fatty acids in ryegrass were determined in fresh samples, and in samples dried at room temperature for $26 \mathrm{~h}$, at $50^{\circ}$ for $18 \mathrm{~h}$ or at $100^{\circ}$ for $12 \mathrm{~h}$. The drying of grass resulted in a small increase in palmitic acid and a decrease in linolenic acid in the total fatty acids.

2. Samples of grass dried at $50^{\circ}$ and $100^{\circ}$ were stored at three relative humidities $(\mathrm{rh}<3 \%$, $47 \%$ and $80 \%$ ) for 13 months.

3. There were marked changes in the samples stored at $80 \% \mathrm{rh}$, with an onset of mould growth and a loss of dry matter. The samples stored at lower humidities had no mould.

4. There were two types of change in the fatty acids during storage. The deterioration brought about by mould was accompanied by a decrease in the concentration of linolenic acid and an increase in the concentrations of oleic and linoleic acids. The other type of change observed at the lower humidities resulted in a decrease in the content of linolenic and an increase in the content of palmitic, and did not affect the amounts of oleic and linoleic cells.

5. There was little difference between the changes that occurred in the composition of the total fatty acids of the grass dried at $50^{\circ}$ and of that dried at $100^{\circ}$. The changes that were at all significant appeared to occur less rapidly, particularly in the early months of storage, in the grass dried at the higher temperature for the shorter time.
\end{abstract}

The successful preservation of dried forages in an intact form is of economic importance, and various aspects of this problem were studied intermittently at this Institute and elsewhere, particularly during the Second World War and immediately afterwards. On long storage in this country feeding-stuffs can be affected by moulding, and this aspect of the problem has received much attention (cf. Wright, 194I). The onset of moulding is related to the moisture content of the feeding-stuff and the latter was shown to be a direct function of the relative humidity (rh) of the atmosphere (Snow, Crichton \& Wright, 1944a,b), but the emphasis was usually on prevention of moulding rather than on the changes that occurred in the composition of the material studied. The problem was reinvestigated by Waite (1949), who pointed out that the development of moulding depended on the storage temperature and that the critical humidity derived from laboratory experiments did not necessarily apply under practical conditions where the temperature was normally lower. Changes in the content of some components of the feeding-stuffs were investigated by Snow, Smith \& Wright (I945) and by Snow \& Wright (1945), and deterioration caused by agents other than mould was also considered.

Lipid is a minor but important constituent of roughages (Garton, I960), but any serious investigation of changes in this constituent during storage had to await the development of the new chromatographic techniques. Collins \& Shorland (1944-5) studied the change that occurred in the total amounts of fatty acids and phospholipids in grass during drying and storage periods of relatively short duration. Much later Lea (1957) drew attention to deteriorative reactions involving phospholipids in stored 
foods. Couchman (1959) studied the effect of the temperature of storage on the content of fat extracted with two different solvents from hay and found that the amount of crude fat decreased. Tanhuanpää \& Lindberg (1965) found that the fat content of grain decreased during storage for 2 years and that there was a small but consistent increase in linolenic acid and a decrease in linoleic acid in the total fatty acids. On the other hand, Thafvelin \& Oksanen ( 1966 ) found that during the slow drying and storage of hay there was a consistent decrease in the percentage of linolenic acid in the total fatty acids. It was noted during studies of the metabolism of fatty acids in the rumen of sheep (Czerkawski, Blaxter \& Wainman, 1966) that, in spite of lack of any obvious signs of deterioration, the composition of the fatty acids in a good-quality dried grass tended to change during storage. There was a decrease in the percentage of linolenic acid in the total fatty acids, but no significant change in the content of total fatty acids in the dry matter of the grass. In view of the dramatic effect of linolenic acid on the metabolism in the rumen (Czerkawski et al. 1966), and in view of the large proportion of this acid in the total fatty acids of grass (Lima, Richardson \& Stahmann, 1965), it was desirable to investigate this decrease in linolenic acid in greater detail.

Ryegrass (Lolium perenne) was chosen for the present experiment because it is so widely grown. The object was to dry samples of freshly cut grass in such a way that they would contain 10\% moisture, and to store the dried samples at room temperature at different humidities. An atmosphere with a rh of $80 \%$ would simulate conditions often met with outside in this country, and this level of humidity at room temperature would ensure speedy and prolific mould growth. A rh of about $50 \%$ would effectively eliminate mould growth and would maintain the existing moisture content of the dried grass. In addition the effects of storage under very dry conditions ( $r$ h $<3 \%$ ) were investigated.

\section{EXPERIMENTAL}

Material. Ryegrass, free from clover and cut on I2 July 1965 , was obtained from the Grass and Dairy Husbandry Department of this Institute. It contained $16.9 \%$ dry matter.

Drying procedure. The freshly cut grass $(5 \mathrm{~kg})$ was divided into three portions. One portion $(2 \mathrm{~kg}$ ) was dried in a forced-air oven (Birmingham and Blackburn Construction Co. Ltd) for $12 \mathrm{~h}$ at $100^{\circ}$, and a similar amount was dried for $\mathrm{I} 8 \mathrm{~h}$ at $50^{\circ}$. The remainder was dried at room temperature $\left(23^{\circ}\right)$ for $26 \mathrm{~h}$. The duration of drying at any given temperature was determined by the extent of removal of water, the desired final dry-matter content being about $90 \%$ in the samples dried at $50^{\circ}$ and $100^{\circ}$ and $75 \%$ in the samples dried at room temperature.

The dried grass in the various preparations was cut into lengths of $\mathrm{I}-2 \mathrm{~cm}$ and mixed well. The samples dried at $50^{\circ}$ and $100^{\circ}$ were divided into three equal portions and placed in shallow polythene bags, which in turn were placed (open) in large glass containers provided with ground-glass lids. The humidity of the driest storage vessel was kept at less than $3 \%$ by inclusion of open jars filled with concentrated sulphuric acid. A solution of sulphuric acid with sp.gr. I.35 gave an atmosphere with a rh of 
$47 \%$, and one of sp.gr. 1.20 provided the high rh of $80 \%$. Thus samples of grass dried at $50^{\circ}$ and at $100^{\circ}$ were stored at three different humidities.

The grass dried at room temperature was placed in Kilner jars which were autoclaved at $20 \mathrm{lb} / \mathrm{in}^{2}{ }^{2}$ for ${ }_{1} 5 \mathrm{~min}$ and then sealed. These jars were stored at room temperature and their contents analysed as required.

Analyses. The storage experiment began in the middle of July 1964 and the initial samples were withdrawn I month later, it being assumed that no microbial or chemical changes would take place during that time. Samples were subsequently withdrawn for analysis at 3 -monthly intervals.

The dry-matter content of the samples was determined by drying for $16 \mathrm{~h}$ at $105^{\circ}$, and their nitrogen content was determined by the Kjeldahl method.

Preliminary experiments showed that extraction of the lipids with methanolchloroform (Folch, Lees \& Stanley, 1957) followed by saponification gave a somewhat smaller yield of fatty acids than direct saponification of the grass, although the composition of the total fatty acids was the same by both these methods. Consequently, the total fatty acids were isolated by direct saponification.

The samples of grass $(9 \mathrm{~g})$ were weighed in round-bottom flasks $(250 \mathrm{ml})$, and refluxed for $\mathrm{I} h$ with $100 \mathrm{ml}$ of ethanol-water $(90 \%$, v/v) containing I $\% \mathrm{KOH}$. The contents were cooled to about $50^{\circ}$ and the extracts decanted through muslin. The residues were suspended in $100 \mathrm{ml}$ of warm water $\left(50^{\circ}\right)$ and shaken intermittently. The supernatant fluids were decanted through muslin and the residues shaken with two portions of $50 \mathrm{ml}$ ethanol. The residues were finally shaken with two portions of Ioo $\mathrm{ml} \mathrm{light} \mathrm{petroleum} \mathrm{(b.p.} 40^{\circ}-60^{\circ}$ ). All the extracts were pooled and separated into aqueous and organic phases in large separating funnels. The aqueous phase was extracted twice with portions of $100 \mathrm{ml}$ light petroleum (b.p. $40^{\circ}-60^{\circ}$ ). These lightpetroleum extracts were pooled, washed with $50 \mathrm{ml}$ of $1.0 \% \mathrm{NaHCO}_{3}$ and then discarded. The original aqueous phase and the washings from the light-petroleum extracts were pooled, acidified with $\mathrm{IO} \mathrm{N}^{-} \mathrm{H}_{2} \mathrm{SO}_{4}$ to about $\mathrm{pH} \mathrm{I}_{5} \cdot 5$ and extracted at once with an equal volume of diethyl ether. The aqueous phase was extracted with diethyl ether twice more and the ether extracts were pooled. The ether solutions of the fatty acids were washed with about $20 \mathrm{ml}$ distilled water and the ether was removed on a rotary film evaporator. The residues were weighed.

The methyl esters of the fatty acids were prepared by the method of Kates (1964) and analysed by gas-liquid chromatography (Pye Argon Gas Chromatograph) on columns of Chromosorb W-polyethylene glycol adipate $(9: \mathrm{I}, \mathrm{w} / \mathrm{w})$ at $197^{\circ}$.

The samples remaining after the final analysis of the fatty acids ( 13 months) were analysed for organic matter by ashing at $55^{\circ}$, for lignin (Czerkawski, 1967) and cellulose (Crampton \& Maynard, 1938). Portions of this material were also used for the determination of the in vitro digestibility of the organic matter (Alexander \& McGowan, 1966). 


\section{RESULTS}

The moisture, nitrogen and total fatty acid contents of the grass during storage

Variations in the moisture content of the samples of grass dried at $50^{\circ}$ and $100^{\circ}$ and stored at three humidities $(<3,47$ and $80 \%$ rh) are shown in Fig. I $a, b$. In both samples the moisture content decreased a little at low humidity, remained practically constant at a rh of $47 \%$ and increased rapidly at high humidity. The


Fig. I. Changes in the moisture content $(a, b)$ and nitrogen content $(c, d)$, during storage of grass which was dried at $50^{\circ}(a, c)$ and $100^{\circ}(b, d)$. $\bigcirc-0$, stored in an atmosphere with $<3 \% \mathrm{rh}$; - stored in an atmosphere with $47 \% \mathrm{rh}$; - stored in an atmosphere with $80 \%$ rh. rh, relative humidity.

nitrogen content in the grass dry matter behaved similarly, showing little change except in grass stored at $80 \%$ rh, where the nitrogen content expressed as a percentage of the dry matter increased during storage (Fig. I $c, d$ ).

Over the same period the moisture and nitrogen contents of the samples that were 
dried at room temperature and autoclaved remained constant at $25^{\circ} 9 \pm 0 \cdot I$ and $I \cdot 58 \pm$ $0.01 \%$ respectively.

The fatty acid content of the grass did not increase or decrease regularly during storage at the three different humidities, but at $80 \%$ th the spread of values was much greater than at the two lower humidities and some abnormally high values were obtained. The results after $1-13$ months' storage, given as means of the five determinations in each series, together with the corresponding standard errors, are shown in Table I. The content of fatty acids increased slightly though not always significantly with increase in humidity. The concentration of fatty acids was greater when the samples were dried for a short time at $100^{\circ}$ than when they were dried for a longer time at $50^{\circ}$. This difference was statistically significant when the samples were stored at low or medium humidity, but was not significant at high humidity.

Table I. Mean concentrations of total fatty acids and their standard errors in grass stored for $\mathrm{I}, 4,7$, 10 and I 3 months (expressed as \% dry matter)

Temperature
of drying

$\left({ }^{\circ} \mathrm{C}\right)$

50

roo

Difference

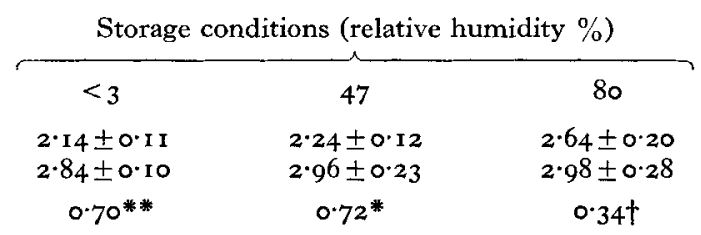

* $P<0.05$ ( $t$ test).

** $P<0.01$ ( $t$ test).

$\uparrow$ The samples stored for 7 months gave an abnormally high yield of fatty acids $(3.3$ and $3.8 \%$ respectively). The difference was not significant.

Table 2. Composition (\%) of the fatty acids in ryegrass immediately before and after drying under different conditions

$\begin{array}{lcccc}\text { Fatty acid } & \text { Fresh grass } & \begin{array}{c}\text { Grass dried } \\ \text { at } 23^{\circ} \text { and } \\ \text { autoclaved }\end{array} & \begin{array}{r}\text { Grass dried } \\ \text { at } 50^{\circ}\end{array} & \begin{array}{r}\text { Grass dried } \\ \text { at } 100^{\circ}\end{array} \\ \text { Palmitic } & 11.8 & 13.2 & 16.2 & 15.0 \\ \text { Stearic } & 1.5 & 1.3 & 1.6 & 1.8 \\ \text { Oleic } & 2.2 & 2.0 & 1.6 & 2.5 \\ \text { Linoleic } & 12.7 & 13.5 & 12.8 & 12.4 \\ \text { Linolenic } & 70.0 & 66.9 & 62.7 & 62.8\end{array}$

Small amounts of $\mathrm{C}_{12}, \mathrm{C}_{14}$ and unidentified acids are not included in this table.

The composition of fatty acids in grass after drying and during storage

The conditions of drying had only a small effect on the composition of the fatty acids in grass (Table 2). There was a small increase in the percentage of palmitic acid and a decrease in the percentage of linolenic acid when fresh grass was dried at room temperature. These changes were somewhat greater when the grass was dried at higher temperatures, but there was no difference between the fatty acid composition of grass dried at $50^{\circ}$ and of that dried at $100^{\circ}$.

The variation in the composition of the unsaturated $\mathrm{C}_{18}$ acids during storage is shown in Fig. 2. Linolenic acid decreased rapidly when the samples dried at $50^{\circ}$ were 
stored at $80 \%$ th and there was an increase followed by a net decrease of this acid in the samples stored at the lower humidities. The changes were similar in samples dried at $100^{\circ}$, but were generally less extensive (Fig. $2 a, b$ ). With the grass stored at low and medium humidities, the percentage of linoleic acid did not change in samples
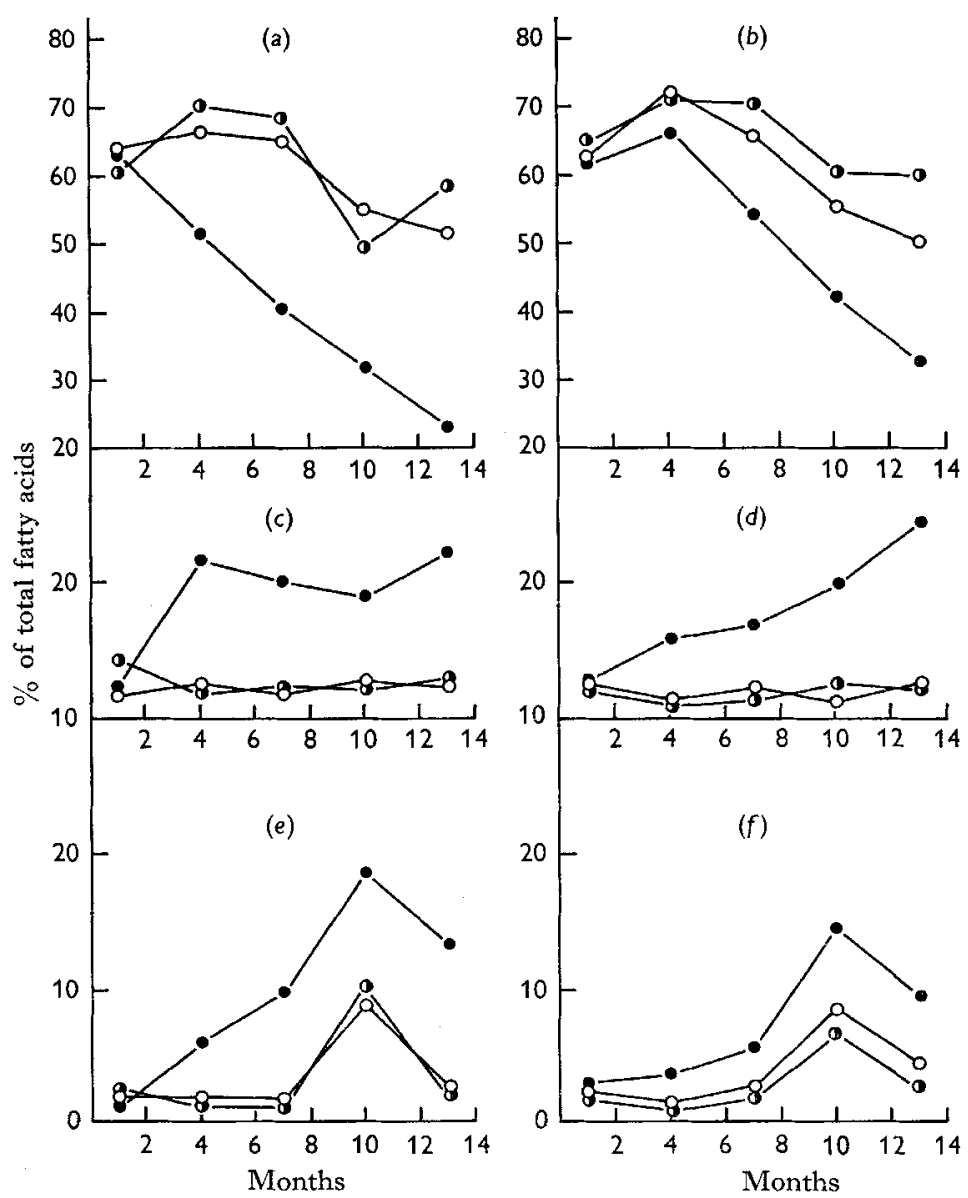

Fig. 2. Changes in composition of unsaturated $\mathrm{C}_{18}$ fatty acids ( $\%$ of total fatty acids) during storage of grass which was dried at $50^{\circ}(a, c, e)$ and $100^{\circ}(b, d, f), a, b$, linolenic acid; $c, d$, linoleic acid; $e$; $f$, oleic acid; $O-O$, stored at $<3 \% \mathrm{rh} ; 0-0$, stored at $47 \%$ rh; $-O$, stored at $80 \%$ rh. rh, relative humidity.

dried at either $50^{\circ}$ or $100^{\circ}$, but at high humidities the concentration of this acid increased rapidly in samples dried at $50^{\circ}$ and more slowly in samples dried at $100^{\circ}$ (Fig. 2c, $d$ ). There was a marked increase in the proportion of oleic acid in grass stored at $80 \%$ rh, the change in the first 4 months being more rapid in the material that was dried at $50^{\circ}$.

A large amount of oleic acid was present in the samples after ro months of storage at all three humidities but no explanation for this can be offered (Fig. 2e,f).

Stearic acid (Fig. $3 c, d$ ) followed trends similar to those shown by linoleic acid. The 
increases at $80 \%$ rh during the first 6 months were more pronounced when the material was dried at $50^{\circ}$. The differences in humidities of storage did not significantly influence the concentration of palmitic acid (Fig. $3 a, b$ ) in the grass dried at $100^{\circ}$. All the curves relating the concentration of palmitic acid to time of storage showed a minimum at $4-7$ months.

The results of analysis of the samples that were dried at $23^{\circ}$ and autoclaved before storage are summarized in Table 3 . The amounts of linoleic, oleic and stearic acids
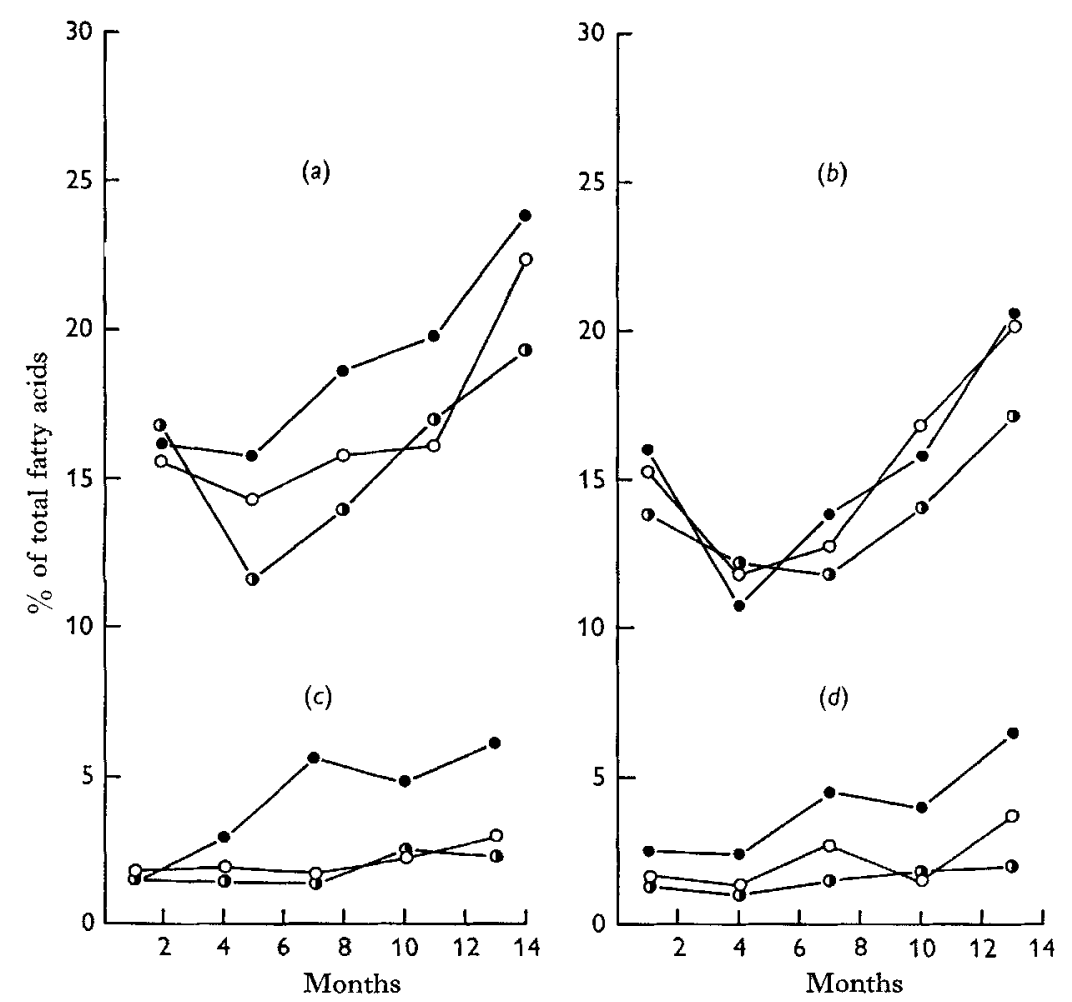

Fig. 3. Changes in the composition of the major saturated fatty acids ( $\%$ of total fatty acids) during storage of grass which was dried at $50^{\circ}(a, c)$ and at $100^{\circ}(b, d)$. $a, b$, palmitic acid; $c, d$, stearic acid; $O-O$, stored at $<3 \% \mathrm{rh} ;-0$, stored at $47 \%$ rh; -0 , stored at $80 \% \mathrm{rh}$. Th, relative humidity.

did not change appreciably. There was a significant decrease in the concentration of linolenic acid and an increase in the concentration of palmitic acid.

The samples also contained small amounts of lauric and myristic acids, traces of fatty acids containing odd numbers of carbon atoms and about $2 \%$ of an unidentified component. The methyl ester of the unidentified material had the retention volume relative to methyl stearate equal to 0.62 on a polythene glycol adipate column at $197^{\circ}$. The concentration of this component had no tendency to change during storage. 


\section{Mould growth}

There was no odour or any visible sign of mould growth in any of the samples after I month. After 4 months the samples dried at $50^{\circ}$ and stored at $80 \%$ rh had a faint fruity odour. The fruity odour became more and more noticeable during further storage at high humidity in samples dried at $50^{\circ}$ and in samples dried at $100^{\circ}$. After Io months these samples became lighter in colour, and examination under a lowpower microscope revealed heavy mould growth. As was expected (Wright, 194I), the samples stored at low or medium humidity showed no mould.

Table 3. Concentrations (\% of total fatty acids) of fatty acids in grass that had been dried at $23^{\circ}$, autoclaved and stored in Kilner jars for varying periods

Period of
storage
(months)
I
4
7
I 3

\begin{tabular}{ccccc}
\multicolumn{4}{c}{ Fatty acid } \\
Palmitic & Stearic & Oleic & Linoleic & Linolenic \\
$12 \cdot 0$ & $1 \cdot 5$ & $2 \cdot 0$ & 14.1 & 67.8 \\
13.1 & $1 \cdot 1$ & $2 \cdot 0$ & 13.9 & 66.9 \\
14.3 & $1 \cdot 4$ & 1.6 & 14.1 & 65.3 \\
17.0 & $2 \cdot 3$ & $2 \cdot 8$ & 14.0 & $61 \cdot 0$
\end{tabular}

Table 4. Concentration (\% dry matter) of cellulose, lignin and ash at the conclusion of the experiment, given as means of values for grass dried at $50^{\circ}$ and $100^{\circ}$

$\begin{array}{cccccc}\begin{array}{c}\text { Storage } \\ \text { conditions }\end{array} & \text { Cellulose } & \text { Lignin } & \text { Ash } & \frac{\text { Cellulose }}{\text { Ash }} & \frac{\text { Lignin }}{\text { Ash }} \\ \text { Control, sealed jars } & 30.7 & 3.26 & 8.46 & & \\ <3 \% \text { rh } & 30.4 & 3.30 & 8.16 & & 0.39 \\ 47 \% \text { rh } & 30.6 & 3.09 & 8.22 & 3.7 & 0.40 \\ 80 \% \text { rh } & 38.4 & 4.51 & 10.86 & 3.5 & 0.38 \\ & & & & \end{array}$

Some characteristics of the samples at the conclusion of the experiment

Irrespective of the conditions of storage the percentages of ash, lignin and cellulose in the samples of grass dried at $50^{\circ}$ were the same as the percentages of ash, lignin and cellulose in the corresponding samples dried at $100^{\circ}$. On the other hand, the concentration of these resistant components in samples stored at the two lower humidities were lower than in the samples stored at $80 \%$ rh (Table 4). The ratios of the concentration of cellulose and lignin to the concentration of ash were approximately the same $(3.65 \pm 0.06$ and $0.40 \pm 0.01$ respectively) whether the samples were stored at high or low humidity.

If it can be assumed that ash and lignin remain intact during storage under the conditions of this experiment, their concentrations can be used to compare changes that occurred in the other components of the grass. This has been done in Table 5, where the various values are given in arbitrary units, calculated by assuming that the combined concentration of ash and lignin was equal to unity. Expressed in this way, the content of crude protein was similar in all samples. There was a considerable loss of dry matter $(24 \%)$ in the samples stored at $80 \%$ rh, which was confined to organic 
matter other than lignin or cellulose, e.g. soluble carbohydrate. The loss of this material was about $50 \%$.

The results of the in vitro determination of digestibility of the samples stored for I 3 months at the different humidities are shown in Table 6 . There was no difference in digestibility whether the samples were dried at $50^{\circ}$ or $100^{\circ}$. The digestibility of the organic matter of the samples stored at the two low humidities was generally about Io units higher than that of the organic matter of samples stored at $80 \% \mathrm{rh}$. The difference between the digestibilities of the lignin-free organic matter of samples stored at low and high humidities was almost as great ( 9 units). The digestibility of samples which were autoclaved at $20 \mathrm{lb} /$ in. $^{2}$ was lower than that of the samples dried at $50^{\circ}$ and $100^{\circ}$ and stored at low humidity, and higher than that of the samples stored at high humidity.

Table 5. Relative composition of grass samples stored for 13 months at different temperatures and different relative humidities $(r h)$

(It has been assumed that the ash and lignin contents remained constant, and the quantities of various components were calculated in weight units per unit weight of ash + lignin. The proportion of ash to lignin was $0.7-0.3$ ).

\begin{tabular}{|c|c|c|c|c|c|c|}
\hline \multirow[b]{2}{*}{ Component } & \multicolumn{3}{|c|}{ Dried at $50^{\circ}$} & \multicolumn{3}{|c|}{ Dried at $100^{\circ}$} \\
\hline & $<3 \%$ rh & $47 \%$ rh & $80 \% \mathrm{rh}$ & $<3 \%$ rh & $47 \% \mathrm{rh}$ & $80 \% \mathrm{rh}$ \\
\hline (a) Dry matter & $8 \cdot 47$ & $8 \cdot 79$ & $6 \cdot 43$ & $8 \cdot 29$ & 9.07 & $6 \cdot 66$ \\
\hline (b) Cellulose & 2.52 & $2 \cdot 77$ & $2 \cdot 48$ & $2 \cdot 78$ & $2 \cdot 69$ & $2 \cdot 5 I$ \\
\hline $\begin{array}{l}\text { (c) Crude protein } \\
(\mathrm{N} \times 6.25)\end{array}$ & 0.81 & 0.84 & 0.95 & 0.90 & 0.95 & 0.95 \\
\hline (d) Moisture & 0.31 & 0.88 & $2 \cdot 72$ & 0.20 & 0.77 & $3 \cdot 16$ \\
\hline $\begin{array}{l}\text { (e) Soluble } \\
\text { carbohydrate } \uparrow\end{array}$ & $5 \cdot 14$ & $5 \cdot 18$ & $3 \cdot 00$ & $4 \cdot 61$ & $5 \cdot 43$ & $3 \cdot 20$ \\
\hline
\end{tabular}

'Table 6. Digestibility in vitro of organic matter and of lignin-free organic matter in grass after storage for 13 months

$\begin{array}{ccc}\text { Conditions of storage } & \begin{array}{c}\text { Digestibility† of } \\ \text { organic matter }(\%)\end{array} & \begin{array}{c}\text { Digestibility } \\ \text { lignin-free organic } \\ \text { matter }(\%)\end{array} \\ \text { Autoclaved, sealed jars } & 73 \cdot 7 & 76 \cdot 7 \\ <3 \% \mathrm{rh} & 78 \cdot 6 \S & 81 \cdot 5 \S \\ 47 \% \mathrm{rh} & 78 \cdot 2 \oint & 80 \cdot 9 \S \\ 80 \% \mathrm{rh} & 68 \cdot 3 \S & 72 \cdot 0 \S\end{array}$

$\uparrow$ Determined by the method of Alexander \& McGowan (I966).

$\ddagger$ Calculated on the assumption that lignin remained unchanged during digestion.

$\S$ Means of values for samples dried at $50^{\circ}$ and $100^{\circ}$. The pairs of values differed by less than I digestibility unit.

\section{DISCUSSION}

As expected, the moisture content of grass increased at high humidity and, although the nitrogen concentration increased when expressed on a dry-matter basis, its absolute amount, per unit weight of ash and lignin, remained remarkably constant.

Changes in the concentration of total fatty acids in the dry matter were too small to 
be determined with accuracy, but the values obtained suggested that, unlike those of cellulose, ash and lignin, the concentrations of total fatty acids did not increase or decrease regularly during storage and, since there was a loss of about $24 \%$ organic matter in samples stored at $80 \% \mathrm{rh}$, it must be assumed that the fatty acids shared in this loss, although the soluble carbohydrate fraction appeared to have suffered most.

The changes in the composition of the total fatty acids were of two types. The first was associated with mould growth, which led to a marked decrease in the concentration of linolenic acid and to increases in the concentrations of linoleic and oleic acids. The second type of change, observed in samples free from mould, was exemplified by an initial increase in the concentration of linolenic acid followed by a decrease to a level that was below the level at the start of the experiment. The increases or decreases in linolenic acid were invariably compensated for by changes in the concentration of palmitic acid. The inverse relationship between the concentrations of linolenic and palmitic acids is well illustrated by comparing the analyses of the control samples which were autoclaved before storage (Tables 2 and 3 ). Linoleic and oleic acids did not appear to be involved in the second type of change.

The deterioration of the grass during mould growth appeared to be extensive and was accompanied by loss of organic matter.

The results of these studies confirmed the previous observation that there was a change in the composition of fatty acids during storage (Czerkawski et al. I 966). They also showed that ryegrass or forages rich in ryegrass should be dried as rapidly as possible at high temperature, rather than for a long time at low temperature, and should be stored at relatively low humidity.

I am indebted to Miss G. Breckenridge for expert assistance and to $\mathrm{Mr} \mathrm{R}$. H. Alexander of the West of Scotland Agricultural College for determining in vitro the digestibilities of the samples.

\section{REFERENCES}

Alexander, R. H. \& McGowan, M. (I966). F. Br. Grassld Soc. 21, I40.

Collins, F. D. \& Shorland, F. B. (1944-5). N.Z. Fl Sci. Technol. A, 26, 372.

Couchman, J. F. (1959). F. Sci. Fd Agric, 10, 513.

Crampton, E. W. \& Maynard, L. A. (1938). F. Nutr. 15, 383.

Czerkawski, J. W. (r 967). Br. F. Nutr. 2r, 325 .

Czerkawski, J. W., Blaxter, K. L. \& Wainman, F. W. (Ig66). Br. F. Nutr. 2o, 349.

Folch, J., Lees, M. \& Stanley, G. H. S. (1957). F. biol. Chem. 226, 497.

Garton, G. A. (1960). Nature, Lond. I87, 511 .

Kates, M. (1964). F. Lipid Res. 5, 132.

Lea, C. H. (1957). F. Sci. Fd Agric. 8, r.

Lima, I. M., Richardson, T. \& Stahmann, M. A. (1965). F. agric. Fd Chem. 13, 143.

Snow, D., Crichton, M. H. G. \& Wright, N. C. (1944a). Ann. appl. Biol. 31, IOz.

Snow, D., Crichton, M. H. G. \& Wright, N. C. (1944b). Ann. appl. Biol. 3r, Irr.

Snow, D., Smith, J. A. B. \& Wright, N. C. (I945). F. agric. Sci., Camb. 35, 65.

Snow, D. \& Wright, N. C. (1945). F. agric. Sci., Camb. 35, 126.

'Tanhuanpää, E. \& Lindberg, P. (1965). Acta Agric. scand. r5, I7I.

Thafvelin, B. \& Oksanen, H. E. (1966). F. Dairy Sci. 49, 282.

Waite, R. (1949). Ann. appl. Biol. 36, 496.

Wright, N. C. (194I). F. agric. Sci., Camb. 31, I94. 